\title{
Intelligent Irrigation Management System
}

\author{
Wafa Difallah ${ }^{1}$ \\ Faculty of Technology,Laboratory of Energetic in arid \\ zones, Tahri Mohammed University of Bechar \\ Bechar, Algeria
}

Khelifa Benahmed ${ }^{2}$

Faculty of Exact Sciences, Department of mathematics and computer science, Tahri Mohammed University of Bechar Bechar, Algeria

\begin{abstract}
It is widely known that water resources are decreasing around the world. Rapid urbanization, population growth, industries and the expansion of agriculture are increasing demand for freshwater. In most countries, including Algeria, irrigation is the largest consumer of water, with about $70 \%$ of all freshwater withdrawals being used for irrigation. Therefore, it can be said that solving the problem of water scarcity is based on the adjustment of irrigation. The aim of this paper is to shed light on the irrigation systems, how they can be applied, and what are their benefits. With the adoption of solar energy to feed the system; this energy source is strongly available in arid zones.
\end{abstract}

Keywords-Internet of things; irrigation; soil; solar; water; wireless sensor network; intelligent

\section{INTRODUCTION}

Irrigation is strongly linked to food security. This sector is largely affected by water crisis. Algeria, like all African countries, is largely affected by the scarcity of water. In order to emerge from this crisis, further efforts should be made to develop the irrigation process. The integration of new technological developments such as wireless sensor networks and the Internet of Things are among the most important solutions to this crisis. Besides, solar power can be used to resolve energy constraints problem of WSN implementation.

In this paper an intelligent irrigation management system will be proposed.

The rest of the paper is organized as follows. Section 2 presents a literature review of smart irrigation system implementation. Then we will deal with irrigation strategies in section 3, followed by smart irrigation technologies in section 4. Intelligent irrigation management system architecture will be discussed in section 5; next we have results and discussion in section 6 before conclusion in section 7 .

\section{RELATED WORKS}

Following the critical and urgent nature of water resource problem, several studies have been proposed.

In [1] authors have found an important theory, which is "the optimal irrigation time exists when the rate of water loss

\author{
Fateh Bounnama ${ }^{3}$, Belkacem Draoui ${ }^{4}$ \\ Faculty of Technology,Laboratory of Energetic in arid \\ zones, Tahri Mohammed University of Bechar \\ Bechar, Algeria
}

\author{
Ahmed Saaidi $^{5}$ \\ Faculty of Exact Sciences, Department of mathematics and \\ computer science, Tahri Mohammed University of Bechar \\ Bechar, Algeria
}

is equal to the uniform inflow rate equivalent to the maximum infiltration requirement".

Sutar, S. et al. [2] developed an environment for drip irrigated agriculture and fertilizer tank control using WSN technologies and Ant Colony Algorithm to make the aggregation energy efficient.

Li-Ming, Z. et al. [3] proposed an auto water-saving irrigation based on wireless sensors networks and multi-source information fusion technology based on entropy.

A Microcontroller based controlled remote irrigation system for the agricultural plantation was developed by Kumbhar, S.R. and Ghatule, A.P.. [4]

To prove the importance of using WSN in the irrigation field, a comparison between automated drip irrigation system and non-automated drip irrigation system was done by Soorya, E. et al.. [5]

For the same purpose, Gao, L. et al. [6] combined wireless sensor network with fuzzy control system in an intelligent water-saving irrigation system to realize a remote on-line monitoring and controlling.

Mohammad, F.S. et al. [7] implemented an intelligent irrigation system under a drip irrigation system for the irrigation of tomato crops.

Tiny OS system was used in [8] for simple and cost effective smart irrigation system.

Another design of a low-cost remote monitoring system for agricultural ecosystems was implemented and validated by Kumar, J.P. et al. [9]

In [10], Shahidian, S. et al. validated a smart irrigation controller in a lettuce crop grown in a greenhouse using EC-5 Echo sensors.

In [11], a smart phone application was developed to quickly view soil moisture deficit, weather measurements, and the ability to input applied irrigation amounts into an online evapotranspiration-based irrigation scheduling tool.

To minimize power consumption and resolve the problem of energy constraint of wireless sensor network devices, solar 
energy was used to feed irrigation management system in [12] and [13]. This energy resource was also used in [14] to power a soil moisture detector.

\section{IRRIGATION METHODS}

Irrigation takes many forms [15]. According to the way of transporting water and its application to the soil, we have: surface irrigation, drip irrigation and sprinkler irrigation.

There are many factors which must be taken into account in the choice of an irrigation method [16]. Table 1 below, represents a comparison between different irrigation strategies.

TABLE I. COMPARISON OF DIFFERENT IRRIGATION STRATEGIES

\begin{tabular}{|c|c|c|c|}
\hline & $\begin{array}{l}\text { Surface } \\
\text { irrigation }\end{array}$ & $\begin{array}{l}\text { Drip } \\
\text { irrigation }\end{array}$ & $\begin{array}{l}\text { Sprinkler } \\
\text { irrigation }\end{array}$ \\
\hline $\begin{array}{l}\text { Recommended } \\
\text { crops }\end{array}$ & $\begin{array}{l}\text { The rice fields, } \\
\text { the pastures } \\
\text { (alfalfa, clover), } \\
\text { arboriculture } \\
\text { (citrus, banana), } \\
\text { cereals. }\end{array}$ & $\begin{array}{l}\text { line crops } \\
\text { (vegetables, } \\
\text { fruits), } \\
\text { arboriculture, } \\
\text { vine }\end{array}$ & $\begin{array}{l}\text { line crops, field } \\
\text { crops and tree } \\
\text { crops }\end{array}$ \\
\hline $\begin{array}{l}\text { Appropriate } \\
\text { soil type }\end{array}$ & $\begin{array}{l}\text { Silty and clay } \\
\text { soils }\end{array}$ & $\begin{array}{l}\text { Clay and sandy } \\
\text { soils }\end{array}$ & $\begin{array}{l}\text { perfectly adapts } \\
\text { to most types of } \\
\text { soil }\end{array}$ \\
\hline Equipment & $\begin{array}{l}\text { Pump, } \\
\text { Irrigation } \\
\text { networks, } \\
\text { sprinklers, } \\
\text { Water cannons, } \\
\text { Self-propelled } \\
\text { sprinklers, } \\
\text { drippers }\end{array}$ & $\begin{array}{l}\text { The pumping } \\
\text { unit } \\
\text { control unit } \\
\text { Main and } \\
\text { secondary } \\
\text { pipelines } \\
\text { Ramps } \\
\text { Drippers or } \\
\text { distributors. }\end{array}$ & $\begin{array}{l}\text { the pumping } \\
\text { unit } \\
\text { main and } \\
\text { approach } \\
\text { pipelines } \\
\text { the ramps } \\
\text { the sprinklers. }\end{array}$ \\
\hline Workforce & Large workforce & $\begin{array}{l}\text { Workforce } \\
\text { economy }\end{array}$ & $\begin{array}{l}\text { Workforce } \\
\text { economy }\end{array}$ \\
\hline Cost & $\begin{array}{l}\text { low cost of } \\
\text { energy and } \\
\text { investment }\end{array}$ & $\begin{array}{l}\text { low cost of } \\
\text { energy and } \\
\text { investment }\end{array}$ & $\begin{array}{l}\text { High cost of } \\
\text { energy and } \\
\text { investment }\end{array}$ \\
\hline
\end{tabular}

\section{SMART IRRIGATION TECHNOLOGIES}

Traditional irrigation strategies are not satisfactory for dealing with the shortage of irrigation water, this sector must benefit from modern technological advances. In this section the two main technologies that have rationalized the field of irrigation will be presented: wireless sensor networks and the Internet of Things.

\section{A. Wireless Sensor Networks (WSN)}

Several technologies can be integrated in the field of irrigation such as sensor networks that constitute a set of sensor nodes dispersed in a geographical area to monitor a phenomenon. Each sensor node is composed of a: processing unit, detection unit, energy unit and transmission unit. In the field of irrigation several varieties of sensors can be used:

- Soil moisture $(10 \mathrm{SH}, \mathrm{EC}-5, \ldots)$

- Humidity (SHT75, HS220, ...)

- Air temperature (TDR-3A, ...)

- Soil temperature (200ss , ...)

- Light intensity $($ On9558, ...)
- Carbon dioxide (GMW120,...)

- Precipitation (Rain Bird RSD-CEx, ...)

- Wind speed and direction (CM-100 compact, ...)

- $\quad$... etc.

\section{B. Internet of Things (IoT)}

The Internet of Things is also a technology that has rationalized several areas and not just the irrigation field. This diversity of application areas involves the diversity of objects connected to this network (sensor, drone, smartphone, etc.).

The number of these objects may exceed 50 billion in 2020. With the advent of the Internet of Things - the word that was first used by Kevin Ashton in 1990- the internet is acquiring a third dimension: in addition to the ability to connect anytime and anywhere, it is now possible to connect with any smart object (see Fig. 1).

There are different types of devices connected to the Internet of things network, or which connect other objects to the Internet such as: identification objects (bar codes, RFID markers,), sensors, drones, UAV (Unmanned Aerial Vehicle), smartphones and tablets (see Fig. 2.).

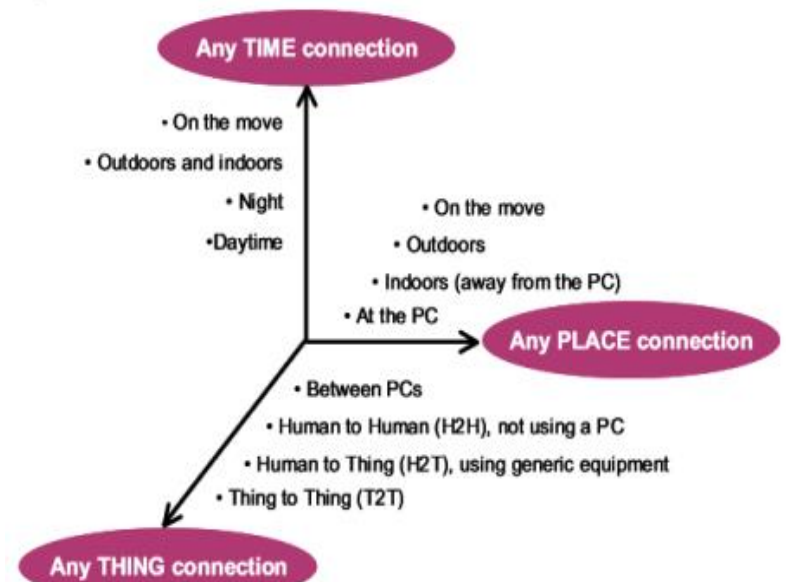

Fig. 1. IoT, A New Dimension [17].

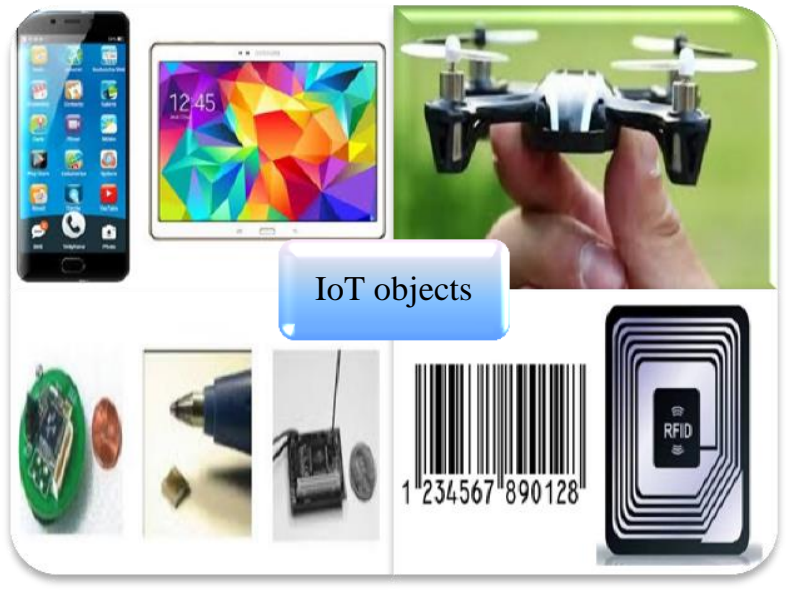

Fig. 2. Iot Objects. 


\section{Integration of WSN in an IoT Network}

The determination of plants water needs is based on climatic parameters such as temperature, humidity, wind speed, etc. These parameters are detectable by specific sensors that are part of a WSN. These components are the basis for the development of any irrigation management system.

In an intelligent irrigation system, WSNs can be integrated into an IoT network, where the sensors will be hosts of the internet and not just data collection tools.

As it is mentioned in [18], this integration is feasible by 02 approaches:

1) Proxy integration: In this approach the base station is the only node connected to the internet, it acts as a proxy that represents an interface between the internet and the sensor nodes associated with it.

2) Integration by adaptation of the TCP / IP standard: In this integration architecture, the sensor network is fully open on the internet and the sensor nodes become real hosts of the Internet, addressable, and having the same concessions as an ordinary host. The projection of the TCP / IP standard as it is on the sensor networks is almost impossible, which necessitates adapting IP-based communication standards, and even developing new mechanisms that are inspired by them, and which would be alerted to the constraints of sensor networks in the new generation of the Internet (the Internet of Things).

\section{ARCHITECTURE OF INTELLIGENT IRRIGATION MANAGEMENT SYSTEM}

Generally, an intelligent irrigation system takes place in three levels (see Fig. 5):

\section{A. Data Collection Level}

Different Sensors can be used to collect environmental data. In this level, We have also the possibility to use solar energy powered sensors or solar powered sensor board such as "Waspmote" which can support 14 different sensors [19] (see Fig. 3 ).

The gateway transmits the data collected by the sensor nodes to the controller to decide an irrigation action. For example, if the sensed temperature or humidity is below predefined thresholds, then activate the irrigation system. In this regard, Zigbee 802.15.4 communication model is used. It is the most suitable communication protocol for this type of application. It allows the transmission of small amount of data (environmental data) over long distances and with the minimal possible power consumption.

The user or manager of the irrigation system can control the irrigation process through smart phone, computer, or tablet.

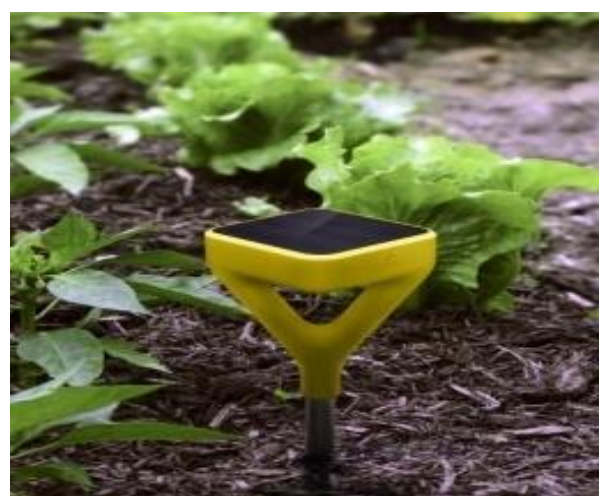

(a) Edyn Soil Moisture Sensor [20]

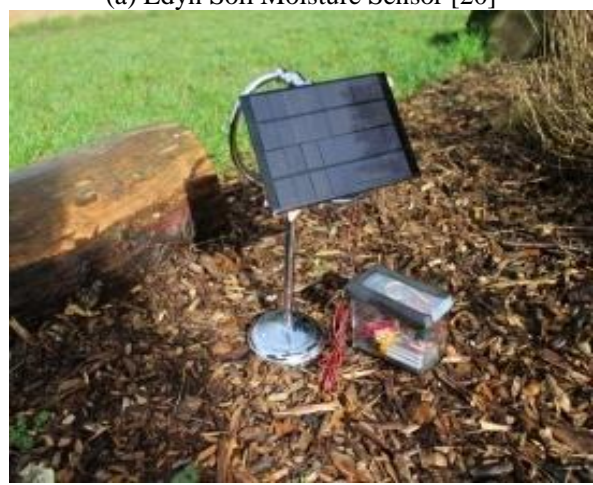

(b) TMP102 Temperature Sensor [21]



(c) Tiny Solar BLE temperature and humidity sensor [22]

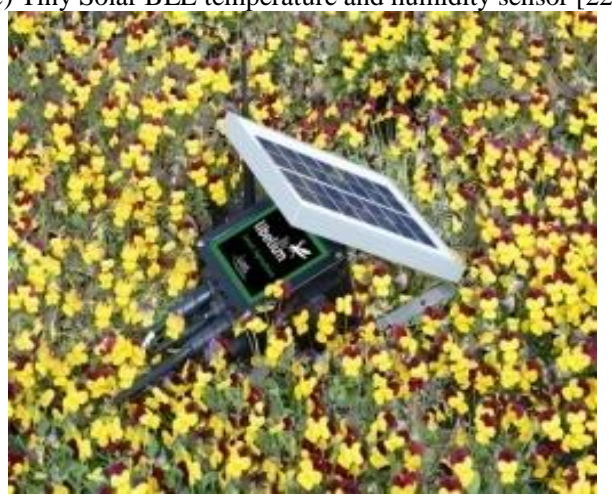

(d) Waspmote Plug \& Sense [23]

Fig. 3. Solar Powered Sensors. 


\section{B. Control Level}

In this level, the microcontroller compares the sensed data with predefined threshold values. If the microcontroller finds that the sensed values are below a predefined threshold values then the auto irrigation system will be activated, otherwise the system stays inactive until the comparison gives the opposite result (see Fig. 4).

The choice of threshold values depends on many factors such as climatic conditions, soil texture, plant types, and irrigation method.

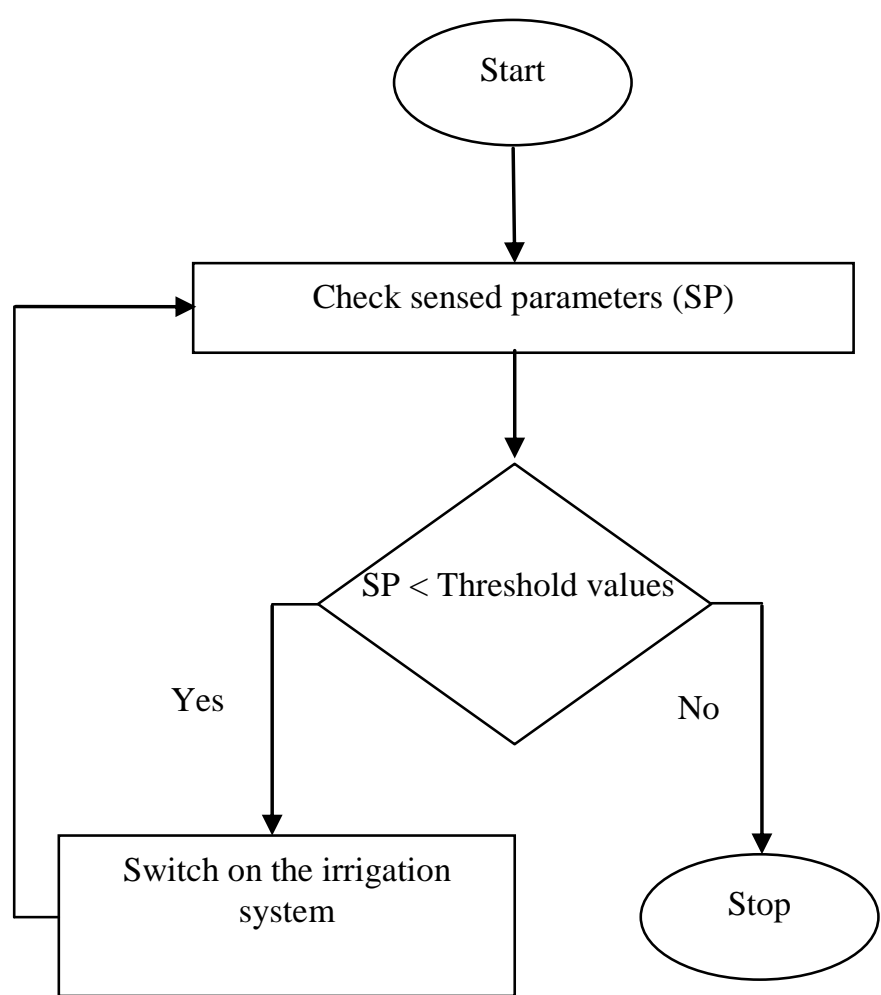

Fig. 4. Flowchart of the Microcontroller.

\section{Solar Powered Water Pumping Level}

To pump water from the source to the storage tank, solar panels must be mounted near the pump; a regulator is used to charge a set of batteries to feed the pump at the source in order to pump the water into the storage tank.

In this step, Different devices are necessary: Source, pump, photovoltaic panels, motor pump-set, mounting structures and tracking system, controller (regulator), inverter (to change the direct current from the solar panels into alternating current for the pump), and water distribution system.

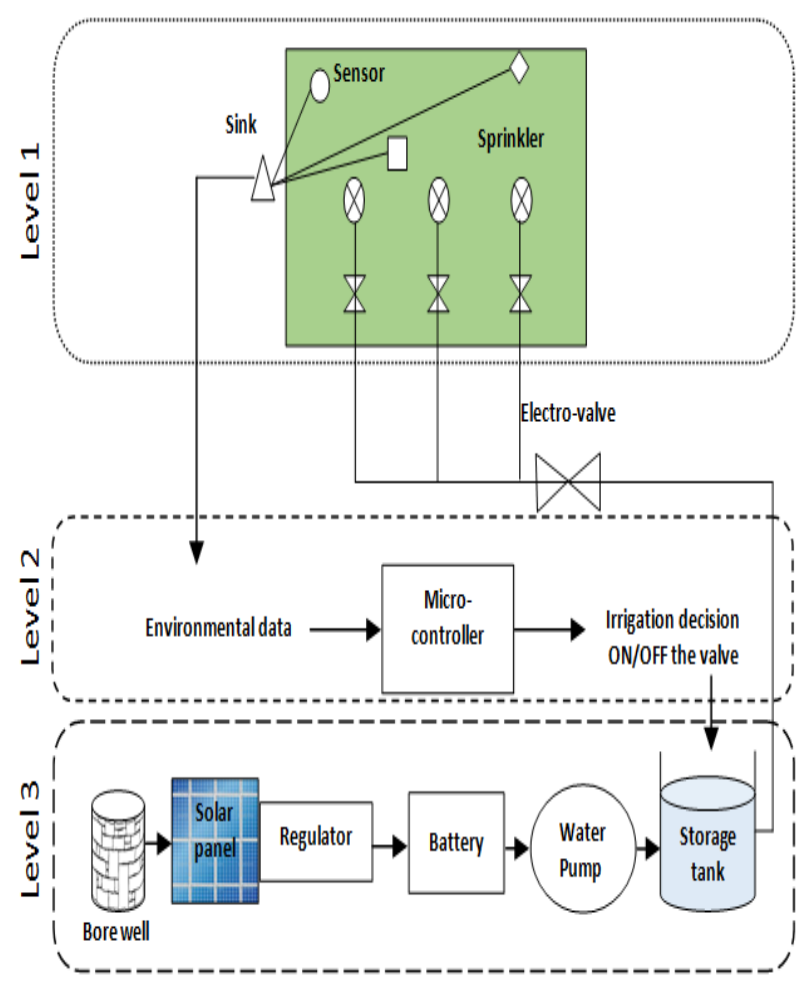

Fig. 5. Intelligent Irrigation Management System Architecture.

\section{ARCHITECTURE OF INTELLIGENT IRRIGATION MANAGEMENT SYSTEM}

The use of proper method of irrigation and its control is very important to reduce water consumption. Automation of irrigation system by monitoring soil moistures and other crop parameters using wireless sensor networks and the Internet of Things is one of the most promising applications that can provide optimal water use efficiency.

Implementation of smart systems in the irrigation field is based on the use of a combination of sensors such as temperature, wind speed and humidity.

Wireless communication and real time information provided by these systems play an important role in estimating the amount of water needed to meet the crop requirements, especially when it became part of the Internet of Things (IoT).

In this research axis, every day there are new technological developments, so it is difficult to develop a unified system adapted to all situations, but that does not prevent the establishment of some basic rules for the construction of a typical system: 
- The system must be sensitive to climate change

- The system must be able to adapt with any type of plant and be effective during the different stages of growth.

- The system must be reliable with any irrigation strategy.

- The communication interface between the network and the end user should be as simple as possible.

\section{CONCLUSION}

Reduce water consumption through the use of intelligent technologies such as wireless sensor networks and the Internet of Things is one of the most promising applications to automate the irrigation process.

In this proposal, the Internet of Things technology is integrated as a communication tool, in addition to the use of solar energy not only to pump water from the source to the storage tank as it is already known, but also to feed the system and deal with the problem of energy constraints of sensor networks.

Since the system is a combination of three technologies (sensor networks, the Internet of Things and solar energy), therefore, it will benefit from the advantages of each technology, to mention but a few:

- The use of real time information to adjust irrigation strategies for any condition.

- Easy installation.

- Minimize labor and time needed to control the irrigation process

- The system guarantees higher productivity with efficient use of water.

- Automation of the irrigation control process by using the detected environmental parameters

- The sun is a stable and reliable source of energy. Fuel supply, transportation or rising operating costs are no longer a concern.

- Solar energy is a source of clean and inexhaustible energy.

\section{REFERENCES}

[1] Dassanayake et al. Water saving through smarter irrigation in Australian dairy farming: Use of intelligent irrigation controller and wireless sensor network, paper presented at the 18th World IMACS / MODSIM Congress (2009) Cairns, Australia. From http://mssanz.org.au/modsim09.

[2] S. Sutar, et al. Irrigation and Fertilizer control for Precision Agriculture using WSN: Energy Efficient Approach. International Journal of Advances in Computing and Information Researches, 1(1) (2012).
[3] Z. Li-Ming, et al. The System of Water-Saving Irrigation based on WSN and MSIF. International Journal of Computer Science Issues, 9(6) (2012).

[4] S.R. Kumbhar and A.P. Ghatule, Microcontroller based Controlled Irrigation System for Plantation, Proceedings of the International MultiConference of Engineers and Computer Scientist, 2 (2013) Hong Kong.

[5] E. Soorya, et al. Smart drip irrigation system using sensor networks. International Journal of Scientific \& Engineering Research, 4(2) (2013).

[6] L. Gao, et al. An Intelligent Irrigation System Based on Wireless Sensor Network and Fuzzy Control, JOURNAL OF NETWORKS, 8(5) (2013).

[7] F.S. Mohammad, et al. Adoption of an intelligent irrigation scheduling technique and its effect on water use efficiency for tomato crops in arid regions, Australian Journal of Crop Science, AJCS, 7(3) (2013) 305313.

[8] P. Alagupandi, et al. Smart Irrigation System for Outdoor Environment using Tiny OS. Paper presented at the International Conference on Computation of Power, Energy, Information and Communication (ICCPEIC), IEEE (2014).

[9] J.P. Kumar, et al. Implementing Intelligent Monitoring Techniques in Agriculture Using Wireless Sensor Networks, International Journal of Computer Science and Information Technologies, 5 (4) (2014) 57975800.

[10] S. Shahidian, et al. Smart irrigation control using inexpensive capacitance probes, Proceedings International Conference of Agricultural Engineering (2014) Zurich. From www.eurageng.eu.

[11] A.C. Bartlett, et al. A smart phone app to extend use of a cloud-based irrigation scheduling tool. Computers and Electronics in Agriculture 111, Elsevier (2015).

[12] J. Gutiérrez, et al. 2013. Automated Irrigation System Using a Wireless Sensor Network and GPRS Module. IEEE transactions on instrumentation and measurement.63, 1 (Jan.2014), 166-176. DOI= 10.1109/TIM.2013.2276487.

[13] W.Difallah et al. 2018. Design of solar powered smart irrigation system (SPSIS), International Conference on Software Engineering and Information Management. (ICSIM2018, January 4-6, 2018, Casablanca, Morocco ). ACM.

[14] M.H. Ariff and M.Z. Ibrahim, Solar Powered Soil Moisture Detector. Latest trends on communications and information technology,79-83.

[15] W. Difallah, et al. Implementing wireless sensor networks for smart irrigation. Taiwan Water Conservancy, 65 (3) (2017).

[16] W. R. Walker. SIRMOD III- Surface Irrigation Simulation, Evaluation and Design-Guide and Technical Documentation. (2003).

[17] ITU. Internet Reports 2005: The Internet of Things .2005. from http://www.itu.int/osg/spu/publications/internetofthings/InternetofThing s_summary.pdf

[18] S.Sahraoui. Mécanismes de sécurité pour l'intégration des RCSFs à l'IoT (Internet of Things) "Security Mechanisms for Integrating WSNs into IoT (Internet of Things)". (2016).

[19] R.,Khan et al. Wireless Sensor Network Based Irrigation Management System for Container Grown Crops in Pakistan. World Applied Sciences Journal, 24(8) (2013).

[20] Edyn soil moisture sensor. From https://www.gardeners.com/buy/edyngarden-soil-moisture-sensor-wifi-solar-powered/8592711.html

[21] TMP102 temperature sensor. From http://www.instructables.com/id/Solar-Powered-Remote-TemperatureSensor/

[22] Tiny Solar BLE temperature and humidity sensor. From http://www.mouser.com/ds/2/100/CYALKIT-E03_Kit_Guide968035.pdf

[23] Waspmote Plug \& Sense. From http://www.libelium.com/smartagriculture-monitoring-greenhouse-conditions-to-develop-new-productsin-the-food-industry/ 